tion of the great nerve-centres in the case under consideration. The fingers are in the position which belongs to incipient "bird's claw" deformity-the "main en griffe" of the French writers. The contraction which gives rise to this position is in certain muscles of the forearm, and it may seem as if this contraction might be owing to irritation in some part of one or other of the great nerve-centres. In reality, however, it has been shown by M. Duchenne (de Boulogne) that this contraction is the direct result of atrophy of the interossei and lumbricales muscles. This atrophy disturbs the balance of power, and allows the simple "tonicity" of the antagonist muscles (the common extensor and the deep and superficial flexors of the fingers) to come into play, and hence the contraction in question ; for M. Duchenne has found that the action of the common extensor of the fingers is to extend, not all the phalanges, but only the first phalanx, and that the action of the superficial and deep flexors of the fingers is to bend, not the first phalanx, but only the second and third phalanges. He has found, in fact, that the interossei and lumbricales muscles (some of the muscles wasted in the present case) have an important office to perform in the movements of the fingers, bending the first phalanx, and extending the second and third phalanges.

In the case in question there is an utter absence of all true "head symptoms" and all true "spinal symptoms." The cerebro-spinal nervous system would appear to be perfectly healthy; as, indeed, is the rule in all cases of the kind, even in those which are most marked as to degree.

The more, indeed, the history of Cruveilhier's atrophy is in vestigated, the more clearly does it appear that this disease is in reality a grimary idiopathic affection of the muscles-namely, fatty or granular degeneration, and not a secondary result of some primaxy disorder in any part of the brain or spinal cord.

Whether the vaso-motor system of nerves is primarily affected is a question which is not so easily answered. The original coolness and blueness of the hand showed plainly that the circulation in this part was greatly enfeebled; and this condition is certainly an argument for supposing that there must be some local fault in the vaso-motor system of nerves. Is this fault, then, the cause of the local wasting of the muscles? It is very possible that it may be; but be this so or not, all the evidence, as I read it, goes to show that the disease is not the result of some primary disease in the cerebrospinal system of nerves. And this is the point to which I at present wis? to call attention particularly.

Another point to be noticed in the case under consideration is the perfect conclition of the nutrition generally, except in the affected hand. There was no evidence, not even the slightest, of any cachexy. There was no evidence of that paricular cachexy which is produced by lead-poisoning, and of which one of the most marked symptoms is that atrophied condition of the extensors of the hand which leads to drop-wrist. And this perfect condition of the nutrition, except in the diseased part, is the invariable rule in all cases of Cruveilhier's atrophy, howerer advanced; and this being the rule, there is really no danger of confounding this affection with the muscular atrophy and paralysis resulting from lead-poisoning. Nor are we alone guider to a diagnosis by the peculiar cachexy produced by leadpoisoning; for are there not in cases of lead-poisoning, which have procesded to the extent of causing muscular atrophy and paralysis, unequivocal signs of disorder of the nervous system, as colic, nenralgia, tremor, cramps and other convulsive disturbances, despondency and other signs of mental disorder, and so on-signs which are never present in Cruveilhier's atrophy, except as an accidental complication? Indeed, the help of electro-magnetism is not wanted to complete the diagnosis, though it is no doubt true, as M. Duchenne (de Boulogne) points out, that Faradization tells upon the muscles in Cruveilhier's atrophy, and not in the atrophy resulting from leasi-poisoning.

In a word, Cruveilhier's atrophy seems to be a disease of which the characters are sufficiently distinct to prevent it from being confounded with the atrophy resulting from any form of true paralysis; and it is in the realizing of these cha. racters that its differential diagnosis will be best made out

There is, moreover, a feature in the history of the disease under consideration which has not been mentioned, and which will prevent it from being confounded with another form of muscular atrophy - viz., that which results from what is called muscular rheumatism. Cruveilhier's atrophy is characterized by its stealthiness and indolence. The muscle is half gone before the patient is alive to the fact. But in the atrophy resuiting from muscular rheumatism the case is widely different, and the wasting is always slowly ushered in by much local pain and tenderness. I saw, for example, a few days ago, a clergyman whose left deltoid muscle had nearly disappeared; but in his case there was no possibility of confounding the atrophy of the muscle with that arising from Cruveilhier's disease, for the muscle had been for weeks the seat of much rheumatic pain and tenderness, and at the time of examination it was still in a condition of comparative painfulness and tenderness.

The treatment pursued requires little comment. Its essential part, no doubt, was the Faradization of the atrophied muscles. Upon this point none can have any doubt who are practically acquainted with the results of this mode of treatment in cases of the kind, or who have read what M. Duchenne (de Boulogne) has written on this subject. But I am also disposed to ascribe some part of the credit to the "localized movements" and the kneadings. I do not pretend to decide as to the precise amount of credit assignable to these agencies; but this I may say-that in cases of muscular atrophy, and in cases of paralysis, the progress towards recovery will be much more tedious and unsatisfactory if they are not included in the plan of treatment.

About the medicine used I have no remark to make; and for the rest I will only say, that to my mind the existence of a disease like Cruveilhier's atrophy, in which idiopathic fatty degeneration of muscle is the essential fact, is a reason for supplying an extra amount of lean meat in the food. For is not lean meat the special and peculiar food of muscle?

REPORT OF

\section{CASES OF STRICTURE OF THE URETHRA.}

BY JAMES WHITEFORD, B.A., M.D.

COMMUNTCATED BY

JAMES SYME, F.R.S.E.,

PRONESGOR OF CLINICAM SERGERY, ENIVERSITY OF EDINBURGH.

As an old pupil of Professor Syme, I venture to submit to the profession, through the pages of THE LANCET, the accompanying cases of stricture, treated according to the plan first proposed by that gentleman :-

CASE 1. -José M. M-, aged forty, residing in the city of Medellin, New Granada, had suffered for nineteen years from stricture. During this period be had been from time to time treated by different surgeons, who passed bougies until the stricture became so tight that this resource failed the patient. After sixteen years of suffering, more or less, from occasional attacks of retention of urine, in one very severe attack, accompanied by fever and rigors, perineal fistulæ formed. These fistulous openings were the main outlet for the urine when I saw him first, which was in November, 1859. About a year previous to this he had applied to an English surgeon then resident in the country. This gentleman divided the stricture internally by means of an instrument carrying a concealed lancet-blade, and afterwards continued to pass a full-sized bougie every two or three days, for more than two months. At the end of this time the patient was dismissed as cured. For two months more he continued well, but the stream gradually became smaller, until he had another attack of retention of urine, and again the fistulous openings formed, within little more than four months after the operation referred to.

On examination I found a tight stricture situated imme diately behind the scrotum, which admitted a No. 2 catheter or bougie. Immediately in front of the stricture there was the opening to a false passage, which rendered it difficult to pass any instrument. I recommended him to submit to the operation practised by you; but having experienced no benefit from the other operation, he declined.

In July, 1860, a relative of his came to request me to see him, as he had been then confined to bed for more than a month by another attack of retention of urine, accompanied by the forma. tion of several new fistulæ. As he now signified his readiness to submit to whatever I might advise, I divided the stricture, cutting from the outside upon the grooved director, which I 
had passed through the stricture. The urethra was opened for an inch and a half at the strictured part, and through the opening the short eatheter was passed into the bladder, and retained there for two days. At the end of seven days no urine passed by the wound. The patient recorered without any bad symptom. A month afterwards I passed a No. 11 bougie without difficulty.

More than a year afterwards this same patient had gonorrhcea, which lasted more or less for a month. Six months after his recovery from this, and nearly twelve months after the last time I had passed an instrument, I introduced a No. 11 bougie with ease. And finally, in March, 1863, another year having elapsed since any instrument was passed, I found the urethra in as satisfactory a condition as when $I$ had last examined it. I again passed a No. 11 without any difficulty.

CASE 2.-Dómingo $\mathrm{O}-$ aged sixty-one, a farmer in the province of Antioguia, New Granala, had sufiered for more than twenty years from stricture, with fistulæ in the perineum. For many years he had sought for no relief at the hands of any surgeon, seeing that on the last occasion that he had placed himself under treatment (by an English surgeon)several attempts to pass instruments having proved unavail ing-he had been told that his case was incurable. The urine for many years had passed almost entirely by the fistulous openings.

In March, 1861, I first saw the patient; and on examination I found a tight stricture behind the scrotum, and a contraction at the orifice, which was so narrowed as to admit only a No. 4 bougie. I was unable, after several patient attempts, to pass any instrument into the bladder; but I conld pass a No. 2 through the principal stricture, immediately behind which the point of the instrument was felt to grate against a rough suriace, which impeded its further progress. Substituting the grooved director for the bougie, I divided the stricture upon it, and found several small stones lying immediately behind the stricture, the urethra being sacculated at the part. On removing these, the director was passed into the bladder, and directly struck against a stone. Having satisfied myself of the exist ence of this, and ascertaining at the same time that it was of no great size, I proceeded to practise the operation known as the median operation of lithotomy, using as my director the same instrument, as I had no other. I succeeded, without much trouble, in extracting the stone. The short perineal catheter, being passed into the bladder, was retained for three days, and after its withdrawal the wound gradually healed up. "The stricture at the orifice had been divided previous to this, and a piece of lint kept between the cut edges for four or five days.

Although the patient had been suffering from intermittent fever for a considerable time, with enlarged spleen, and had always experienced aggravation of his ailment whenever $r$ had attempted to pass an instrument before the operation, he had no rigor after it, nor did any of his ague tits return. About a month after, when nearly quite recovered, and the wound being almost closed, he had an attack of acute dysentery, which was then epidemic in the place. From this he re covered, and soon after he was able to resume his avocations in a distant part of the country. A year afterwards I saw him : he had enjoyel good health, and was perfectly free of his old complaint, although he had been exposing himself to all the hardships of a mountaineer's life in that part of the world. He had sometimes been in the saddle from morning till night for more than a week together, exposed to cold and damp. He had not had any instrument passed since I saw him; and yet I found the urethra as wide as when I had last examined him. It admitted a full-sized bougie with ease.

CASE 3.-José M. G- aged forty-three, residing in Medellin, New Granada, had suffered from stricture for eight years, or thereabouts. In December, 1862, he applied to me. I found that the seat of the contraction was behind the scrotum, and that it only admitted a No. 2 bougie. As the history he gave me of his case showed that the stricture had been dilated several times, but that after very short intervals the same state of matters recurred, and the same process had to be repested, each time with greater difficulty to the surgeon and greater suffering to himself, I at once proposed to him the operation of division. To this he did not agree until eight or nine months afterwards, when I was requested to see him, as he was confined to bed and had been in great suffering for about four months. I found that he had been treated during the interval by ailother practitioner, who had applied caustic frequently to the urethra, with the effect of causing intolerable suffering to the patient, both from the application of the caustic and from the retention of the urine which he found always to follow every time it was applied, without, of course, any good result. The urethra was extremely irritable, and the slightest attempt to pass an instrument was followed by serere rigor, headache, and ferer. In August, 1862, I divided the stricture in the usual manner. To bad result followed the operation, the wound closed entireiy within a fortnight, and the intense pain he had been suffering entirely ceased within a Ieri hours after the operation.

In March, 1863, I was able to pass a full-sized instrument without the slightest difficulty, five months having then elapsed since any had been passed.

CAse 4.-Juan A. G-, aged forty-seren, residing at Marinilla, New Granada, had sutfered for fourteen years irom stricture, with fistula in perineo. For some years before he applied to me, which was in September, 1862, he ha.l submitted to all the sufferings usual to such a state of matters, having been under treatment in former years, and for a long time, without experiencing any lasting benefit. The seat of stricture was behind the scrotum; but there was also a tight contraction at the orifice of the urethra, with a large cicatrix upon the glans, which was evidently comnected with this latter. The anterior contracted part idmitterl a Noo. 4 bougie with difficulty, and through the main stricture I was unable at first to pass any instrument. After several patient endeavours I succeded in passing first a No. 1 bongie, and then a No. 2 catheter into the bladder. After dividing the contraction at the orifice, and passing a No. 9 bongie down to the main stricture, I passed the grooved director through it, and divided it. The short catheter, being passed through the wound, was retained for forty-eight hours, and a piece of lint was irept between the elges of the anterior wound for four or tive clays.

The patient made a good recovery, and was quite free from his complaint when I last saw him, five months after the operation. Four months had elapsed since any instrument had. been passed, and a full-sized instrument could be passed with ease.

CASE 5.-Marcos C-, aged fifty-nine, residing in the town of Concepcion, New Granada, had suffered from stricture for about seventeen years. He had been treated by the method of dilatation, with the effect of obtaining relief for a few weeks at a time, the same treatment being aiways repeated. In 1858 he was under the care of an English surgeon, who suceeded in oradually.dilating the urethra at the seat of stricture until a inll-sized bougie eould be passed without difficulty. In about a month after he had been dismissed as cured, on this occacion, he began to suffer from incontinence of urine, with constant dull pain in the loins. When $I$ saw him first (in December, 1852), he was in this condition, and, according to his owa account, he had never had the natural desire to pass urine since this state of matters began, nor had he emptied the bladker for four years, the urine constantly trickling away. The general appearance of the patient was pole and colematons.

The stricture was situated behind the scroturo, and almitted No. 2. I divided it in the usual way, and on passing the short catheter jinto the bladder a large quantity of ammoniacal urine came away, the bladder having evidently been full. Immediately after this the dull pain in the loins disappeared.

The usual after-treatment was followed, and on the fifth day after, the patient, vithout having any rigor, began to suffer from sickness and vomiting, in the course of which he threw up two large round worms.* A close of santonine, followed by castor oil, relieved him of twenty or thirty more of these worms, after which he recovered without any interruption.

For some time after setting up this patient had a little difficulty in retaining his urine, which continued loaded with mucus. After taking doses of the tincture of the muriate of iron for a few days, howerer, both of these morbid symptoms disappeared.

A few days ago, I was told by a person (a countryman of his) who saw him a few months since (in July last) that he has continued quite free from his old complaint, and that he was otherwise in good health.

Edinburgh, Dec. 185-1.

The frequeney of this affection-viz., of the existencs of parasitic rorms in the alimentary canal, and chieffy of the round worm-in the inhabitan of that part of the world is ineredible to one who has not had medical experience amongst them. Persons of all ages are atiezted. I have seen an infant six weeks old romit a worm three inches long. The same circumitance mentioned in Case 5 had oceurred to a patient nearly seventy years of age, whose foot $T$ had amputated, and who suddenly began to suffer in th's way more than six weess after the operation, the wound being nearly heaicd. was at first at a loss to account for the sickness until the appearance of the worins solved the disfocult. 